\title{
The effect of pre-existing maternal obesity on the placental proteome: two-dimensional difference gel electrophoresis coupled with mass spectrometry
}

\author{
Karen Oliva ${ }^{1,2,3}$, Gillian Barker ${ }^{1,2,3}$, Clyde Riley ${ }^{2,3}$, Mark J Bailey ${ }^{1}$, Michael Permezel ${ }^{2,3}$, \\ Gregory E Rice ${ }^{1}$ and Martha Lappas ${ }^{2,3}$
}

\author{
${ }^{1}$ UQ Centre for Clinical Research, The University of Queensland, Brisbane, Queensland, Australia \\ ${ }^{2}$ Department of Obstetrics and Gynaecology and ${ }^{3}$ Mercy Perinatal Research Centre, Mercy Hospital for Women, University of Melbourne, \\ Level 4/163 Studley Road, Heidelberg, Victoria 3084, Australia \\ (Correspondence should be addressed to M Lappas at Department of Obstetrics and Gynaecology, Mercy Hospital for Women, University of Melbourne;
} Email: mlappas@unimelb.edu.au)

\begin{abstract}
Our aim was to study the protein expression profiles of placenta obtained from lean and obese pregnant women with normal glucose tolerance at the time of term Caesarean section. We used two-dimensional difference gel electrophoresis (2D-DIGE), utilising narrow-range immobilised $\mathrm{pH}$ gradient strips that encompassed the broad $\mathrm{pH}$ range of 4-5 and 5-6, followed by MALDI-TOF mass spectrometry of selected protein spots. Western blot and quantitative RT-PCR (qRT-PCR) analyses were performed to validate representative findings from the 2D-DIGE analysis. Eight proteins were altered (six down-regulated and two up-regulated on obese placentas). Annexin A5 (ANXA5), ATP synthase subunit beta, mitochondria (ATPB), brain acid soluble protein 1 (BASP1), ferritin light chain (FTL), heterogeneous nuclear ribonucleoprotein $\mathrm{C}$ (HNRPC) and vimentin (VIME) were all lower in obese patients. Alpha-1-antitrypsin (A1AT) and stress-70 protein, mitochondrial (GRP75) were higher in obese patients. Western blot analysis of ANXA5, ATPB, FTL, VIME, A1AT and GRP75 confirmed the findings from the 2D-DIGE analysis. For brain acid soluble protein 1 and HNRPC, qRT-PCR analysis also confirmed the findings from the 2D-DIGE analysis. Immunohistochemical analysis was also used to determine the localisation of the proteins in human placenta. In conclusion, proteomic analysis of placenta reveals differential expression of several proteins in patients with pre-existing obesity. These proteins are implicated in a variety of cellular functions such as regulation of growth, cytoskeletal structure, oxidative stress, inflammation, coagulation and apoptosis. These disturbances may have significant implications for fetal growth and development.
\end{abstract}

Journal of Molecular Endocrinology (2012) 48, 139-149

\section{Introduction}

There is no disputing the extent of the worldwide obesity epidemic (Chu et al. 2008, Colagiuri et al. 2010). The proportion of women who are obese at the beginning of pregnancy has dramatically increased (Heslehurst et al. 2010). Obesity in pregnancy is associated with substantially increased risks for both mother and infant (Heslehurst et al. 2008). Gestational diabetes, pre-eclampsia, Caesarean section, instrumental vaginal delivery, birth trauma and pelvic floor damage are increased in the mother (Sebire et al. 2001, Bhattacharya et al. 2007). Infants born to overweight and obese mothers are often macrosomic (Ehrenberg et al. 2004, Surkan et al. 2004) with increased adiposity (Hull et al. 2008). Perhaps of greatest importance for the health system as a whole is that these infants are at increased risk of later metabolic disease, including obesity, diabetes, cardiovascular disease and certain cancers (Boney et al. 2005, Drake \& Reynolds 2010).

The placenta plays a vital role in the regulation of fetal growth and development during pregnancy. Roles include nutrient supply to the fetus, removal from the fetus of metabolic waste and hormone production. Placental phenotypes for intrauterine growth restriction (McCarthy et al. 2007, Struwe et al. 2010), pre-eclampsia (Hass et al. 2006, Dexlin-Mellby et al. 2010, Zhang et al. 2011) and diabetes in pregnancy (Radaelli et al. 2003, Zhao et al. 2011) have been described, but these have not specifically been studied in the context of maternal obesity. However, animal models have been crucial in delineating the impact of obesity on placental function. For example, maternal obesity and overnutrition alter fetal growth rate and cotyledonary vascularity and angiogenic factor expression in the ewe placenta (Ma et al. 2010). There is, however, a paucity of data on the effect of maternal 
obesity in humans. For this reason, we considered it of interest to determine the effect of pre-existing maternal obesity on the protein expression profiles of human placenta. Thus, the aim of this study was to use twodimensional difference gel electrophoresis (2D-DIGE) to identify novel proteins associated with pre-existing maternal obesity in human placenta. Validation of the 2D-DIGE data will be done by quantitative RT-PCR (qRT-PCR) and western blotting.

\section{Materials and methods}

\section{Tissue collection}

Approval for this study was obtained from the Mercy Hospital for Women's Research (Heidelberg, Australia) and Ethics Committee and informed consent was obtained from all participating subjects. Human placenta was obtained from lean and obese pregnant women with normal glucose tolerance at the time of term Caesarean section before the onset of labour (Table 1). Indications for Caesarean section included repeat Caesarean section or breech presentation. Women with any adverse underlying medical condition (i.e. including asthma, diabetes and pre-eclampsia, polycystic ovary syndrome or thyroid or adrenal abnormalities) were excluded. None of the women conceived by artificial reproductive technology. Lean women were categorised as a body mass index (BMI) of $<25 \mathrm{~kg} / \mathrm{m}^{2}$ and obese patients with a BMI of $>30 \mathrm{~kg} /$ $\mathrm{m}^{2}$. Placenta was collected from patients undergoing Caesarean section only to account for any effects of human labour and delivery on the protein profile. Placenta was obtained within $10 \mathrm{~min}$ of delivery and thoroughly washed in ice-cold PBS to remove any blood. Placental lobules (cotyledons) were obtained from various locations of the placenta; the basal plate and chorionic surface were removed from the cotyledon; and villous tissue was obtained from the middle cross-section. Placental tissue was blunt dissected to remove visible connective tissue and calcium deposits. Tissue samples were snap frozen in liquid nitrogen and immediately stored at $-80^{\circ} \mathrm{C}$.

\section{Sample preparation and DIGE labelling}

Placenta ( $n=6$ lean and $n=6$ obese) was homogenised into DIGE lysis buffer $(30 \mathrm{mM}$ Tris, $7 \mathrm{M}$ urea, $2 \mathrm{M}$ thiourea, 4\% 3-(3-cholamidopropyl)dimethylammonio-1-propane sulphonate (CHAPS)). Proteins were extracted during $1 \mathrm{~h}$ at $4{ }^{\circ} \mathrm{C}$, and lysates were clarified by centrifugation at $25000 \mathrm{~g}$ at $4^{\circ} \mathrm{C}$ for $20 \mathrm{~min}$. The supernatant was precipitated with acetone, and protein extracts were then prepared following the general guidelines recommended for subsequent DIGE labelling. Briefly proteins were precipitated using the 2D clean-up kit (GE Healthcare, Piscataway, NJ, USA) and then buffer was exchanged against DIGE lysis buffer using Vivaspin-2 (3 kDa) concentrators (Sartorius Stedim, Goettingen, Germany) until conductivity could be reduced to below $200 \mu \mathrm{S} / \mathrm{cm}$ and the $\mathrm{pH}$ was adjusted to $\sim 8 \cdot 5$.

A lean pooled sample and an obese pooled sample were obtained (containing $50 \mu \mathrm{g}$ of each sample; $300 \mu \mathrm{g}$ total in each pool). This was then labelled with 400 pmol of Cy3 (obese samples) or Cy5 (lean samples; CyDye DIGE Fluors; GE Healthcare). Labelling was performed on ice and in the dark for $30 \mathrm{~min}$. The reaction was then quenched by incubating with $1.5 \mu \mathrm{l}$ of $10 \mathrm{mM}$ lysine on ice and in the dark for $10 \mathrm{~min}$. The Cy3-labelled obese samples were then combined with the Cy5-labelled lean samples and used for 2D gel electrophoresis analysis as detailed below.

\section{OFF-GEL fractionation}

To perform peptide fractionation according to their $\mathrm{p} I$, the 3100 OFF-GEL fractionator and the OFF-GEL kit (both from Agilent Technologies, Waldbronn, Germany) were used following the manufacturer's

Table 1 Characteristics of the 2D-DIGE study group. Values represent mean \pm S.E.M.

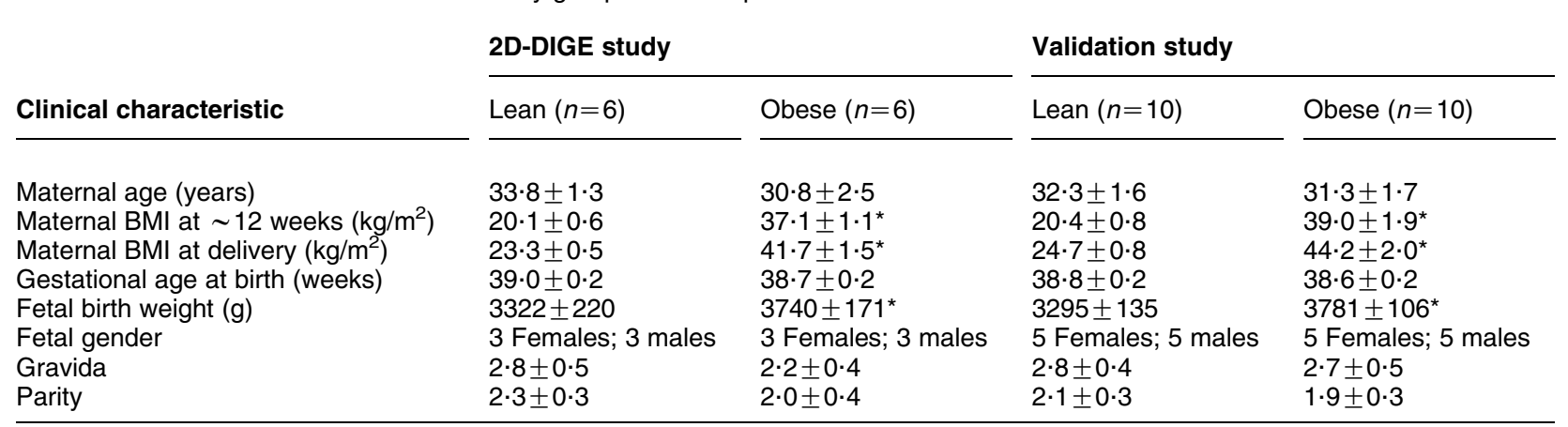

${ }^{\star} P<0.05$ vs lean (Student's $t$-test). 
instructions. The device was set up for the 12 fractions separation by using a $13 \mathrm{~cm}$ long immobilised $\mathrm{pH}$ gradient (IPG) gel strip with a linear $\mathrm{pH}$ gradient ranging from 4 to 7 . Six hundred micrograms of DIGElabelled placenta (pooled placenta samples from six Cy3-labelled obese and six Cy5-labelled lean) were re-suspended with focusing buffer to a final volume of $1.8 \mathrm{ml}$. One hundred and fifty microlitres of this sample were loaded in each of the 12 wells. The sample was focused using the recommended method for OFF-GEL protein 12 wells fractionation with a maximum current of $50 \mu \mathrm{A}$. The focusing was stopped after total voltage reached $20 \mathrm{kVh}$. After focusing, 50-200 $\mu \mathrm{l}$ of the liquid upper phase sample were recovered for each well and pooled according to their $\mathrm{p} I$. The two fractions used for this study were $4-5$ and 5-6.

\section{D gel electrophoresis and imaging}

The two fractions pools were precipitated with acetone, and protein extracts were then prepared following the general guidelines recommended for subsequent DIGE labelling. Briefly proteins were precipitated using the 2D clean-up kit (GE Healthcare) and then buffer was exchanged against DIGE lysis buffer using Vivaspin 2 $(3 \mathrm{kDa})$ concentrators (Sartorius) until conductivity could be reduced to below $200 \mu \mathrm{S} / \mathrm{cm}$ and the $\mathrm{pH}$ was adjusted to $\sim 8.5$. Proteins were focused on $11 \mathrm{~cm}$, $3 \cdot 9-5 \cdot 1$ and $4 \cdot 7-5 \cdot 9$ IPG strips (Bio-Rad). Strips were rehydrated actively at $50 \mathrm{~V}$ and then focused overnight. IEF was performed for a total of $\sim 35000 \mathrm{Vh}$ at $20^{\circ} \mathrm{C}$. IPG strips were then equilibrated in equilibration buffer $(50 \mathrm{mM}$ Tris-HCl, $6 \mathrm{M}$ urea, 30\% glycerol, $2 \%$ SDS) supplemented with $1 \%$ dithiothreitol to maintain the fully reduced state of proteins, followed by $2.5 \%$ iodoacetamide to prevent re-oxidation of thiol groups during electrophoresis. Proteins were separated on $10 \cdot 5-14 \%$ Criterion Tris- $\mathrm{HCl}$ gels (BioRad Laboratories) at $15 \mathrm{~mA} / \mathrm{gel}$ for $60 \mathrm{~min}, 30 \mathrm{~mA} / \mathrm{gel}$ for $2 \mathrm{~h}$ and $45 \mathrm{~mA} / \mathrm{gel}$ for $30 \mathrm{~min}$ at room temperature until the bromophenol blue dye-front had run off the bottom of the gels.

CyDye DIGE Fluor-labelled protein gels were scanned at $100 \mu \mathrm{m}$ using a Typhoon Trio 9100 (GE Healthcare). The emission filters were Green $532 \mathrm{~nm}$ (Cy3) and Red $633 \mathrm{~nm}$ (Cy5). Gels were automatically aligned and relative protein quantification across lean and obese samples was performed using the Progenesis SameSpots Software 3.3.3420.25059 (Nonlinear Dynamics, Newcastle upon Tyne, UK). Normalisation was performed using the software algorithm. Student's $t$-test was used to calculate significant differences in relative abundances of protein spot features in placenta obtained from lean and obese pregnant women.

The 2D gels were fixed in 50\% methanol, $3 \%$ phosphoric acid and then stained with Colloidal
Coomassie stain and gels spots of interest were excised using a gel pen. Gel spots were then transferred into water for short-term storage at $4{ }^{\circ} \mathrm{C}$. The water was subsequently removed and discarded from each gel plug. Gel pieces were destained by four sequential washes in destaining solution $(10 \mathrm{mM}$ ammonium bicarbonate (AmBic), $50 \%$ acetonitrile (ACN)), followed by two washes in $100 \% \mathrm{ACN}$, and then air dried at room temperature. The gel pieces were rehydrated by adding $10 \mu \mathrm{l}$ of sequencing grade trypsin $(0.02 \mu \mathrm{g} / \mu \mathrm{l}$ (Promega) in $10 \mathrm{mM}$ AmBic) and left to incubate overnight at $37^{\circ} \mathrm{C}$. Digestion was quenched by addition of $2 \mu \mathrm{l}$ of $2 \%$ formic acid (FA).

To avoid labelling bias arising from the varying fluorescence properties of gels at different wavelengths, samples from the same group were run twice in different gels but with the opposite dye labelling pattern. The Cy channels were individually imaged from each of the two gels using mutually exclusive excitation and emission wavelengths.

\section{MALDI-TOF mass spectrometry and protein identification}

Three microlitres of digest supernatant were applied to a Bruker Biosciences Anchorchip MALDI target, prepared with $\alpha$-cyano-4-hydroxycinnamic acid (CHCA; see the thin layer affinity method for CHCA in the Bruker Anchorchip Manual). After 3 min, this solution was removed and the spots were air dried overnight at room temperature. MALDI-mass spectrometry (MS) was performed on a Bruker Microflex MALDI-TOF mass spectrometer (Bruker Daltonics, Bremen, Germany). Peaklists were generated using Flexanalysis (Bruker Daltonics) and were calibrated by utilising trypsin autolytic peptides. Biotools Software (Bruker Daltonics) and the Mascot search engine were used to interrogate the SwissProt database (release: July 2010, 517802 sequences; 182492287 residues) and proteins were identified by peptide mass fingerprinting. Search parameters were: taxonomy: human; MS tolerance, $100 \mathrm{ppm}$; missing cleavages, $\leq 1$; enzyme, trypsin; fixed modifications, carbamidomethylation and variable modifications, oxidation (M). Identifications with Mascot expect probability values $<0.05$ were then manually verified by examination of spectra and/or resubmission of peak lists to Mascot. We took a conservative approach to protein identification and based acceptance on a number of criteria other than these scores. These included theoretical and experimental $M \mathrm{r}$ and $\mathrm{p} I$ being in accord, experimental peptide mass accuracy variation across the mass range and repeatability of identification across different gels. If multiple members of a protein family were identified those with the highest ranked hit were selected. 


\section{RNA extraction and RT-PCR}

Total RNA was extracted from $\sim 100 \mathrm{mg}$ of tissue using Tri reagent according to the manufacturer's instructions (Sigma-Aldrich). RNA concentrations were quantified using a spectrophotometer (Smart Spec; Bio-Rad). RNA quality was determined via the $\mathrm{A}_{260} / \mathrm{A}_{280}$ ratio. One microgram of RNA was converted to cDNA using the SuperScript VILO cDNA synthesis kit (Invitrogen) according to the manufacturer's instructions. The cDNA was diluted tenfold, and $2 \mu \mathrm{l}$ of cDNA were used to perform RT-PCR using Sensimix Plus SYBR green (Quantace, Alexandria, NSW, Australia) and $100 \mathrm{nM}$ of QuantiTect Primer Assays (Qiagen). Pre-validated primers for brain acid soluble protein 1 (BASP1; QT01672923) and GAPDH (QT01192646) were purchased from Qiagen. Average gene $C_{\mathrm{T}}$ values were normalised to the average GAPDH values of the same cDNA sample. The specificity of the product was assessed from melting curve analysis. RNA without reverse transcriptase during cDNA synthesis as well as PCR reactions using water instead of template showed no amplification. Gene expression levels were determined using the comparative threshold cycle $\left(C_{\mathrm{t}}\right)$ method.

\section{Western blotting}

For protein detection by western blot analysis, tissue was homogenised in radioimmuno precipitation assay buffer (1\% SDS, $0.25 \%$ sodium deoxycholate, $1 \%$ Nonidet P-40, $150 \mathrm{mM} \mathrm{NaCl}, 50 \mathrm{mM}$ Tris-HCl, $\mathrm{pH} 7 \cdot 4)$, supplemented with protease inhibitors (1 mM EDTA, $0.5 \mathrm{mM}$ phenylmethylsulfonyl fluoride, $10 \mu \mathrm{g} / \mathrm{ml}$ aprotinin and $5 \mu \mathrm{g} / \mathrm{ml}$ leupeptin). Cellular debris and lipids were eliminated by centrifugation of the solubilised samples at $25000 \mathrm{~g}$ for $30 \mathrm{~min}\left(4^{\circ} \mathrm{C}\right)$. Protein concentration was determined by the BCA Protein Assay (Pierce, Rockford, IL, USA).

Assessment of protein expression was analysed by western blotting as previously described (Lappas et al. 2003). Membranes were incubated with mouse monoclonal anti-alpha-1-antitrypsin (A1AT), Clone 1C2 (SAB4200198; Sigma) at $0.6 \mu \mathrm{g} / \mathrm{ml}$; mouse monoclonal anti annexin A5 (ANXA5; WH0000308M1; Sigma) at $1 \mu \mathrm{g} / \mathrm{ml}$; rabbit polyclonal anti ATP synthase subunit beta, mitochondria (ATPB; HPA001520; Sigma) at $0.2 \mu \mathrm{g} / \mathrm{ml}$; rabbit polyclonal anti stress-70 protein, mitochondrial (GRP75; HPA000898; Sigma) at $0 \cdot 1 \mu \mathrm{g} / \mathrm{ml}$; mouse monoclonal anti vimentin (VIME; clone V9, N1421; Dako) at $2 \mu \mathrm{g} / \mathrm{ml}$; rabbit polyclonal anti-ferritin light chain (FTL; F8556; Sigma) at $1 \mu \mathrm{g} / \mathrm{ml}$; rabbit polyclonal anti-ferritin heavy chain (FTH; F8306; Sigma) at $1.8 \mu \mathrm{g} / \mathrm{ml}$; and mouse monoclonal anti- $\beta$-tubulin (T8328; Sigma) at $1.2 \mu \mathrm{g} / \mathrm{ml}$. The antibodies were diluted in blocking buffer $(5 \%$ skim milk/tris-buffered saline-Tween (TBS-T; 0.05\%)) for
$24 \mathrm{~h}$ at $4{ }^{\circ} \mathrm{C}$. Membranes were stripped and probed with mouse monoclonal anti- $\beta$-tubulin (T8328; Sigma) for normalisation of the data. Membranes were viewed and analysed using the Chemi-Doc system (Bio-Rad). Quantitative analysis of the relative density of the bands in western blots was performed using Quantity One 4.2.1 image analysis software (Bio-Rad). Data were corrected for background and then normalised to $\beta$-tubulin expression.

\section{Immunohistochemistry}

Placenta was placed in embedding cassettes fixed in buffered formaldehyde solution (4\%) and embedded in paraffin. Serial sections ( $4 \mu \mathrm{m}$ thick) were cut and mounted on sections onto superfrost plus slides. Slides were prepared consecutively for each sample. Each site was immunolabelled with each of the antibodies and one was used as a negative control slide. Sections were deparaffinised followed by an antigen retrieval step (boiled in $10 \mathrm{mM}$ citrate buffer, $\mathrm{pH} 6.0$ for $10 \mathrm{~min}$ followed by $20 \mathrm{~min}$ incubation). Endogenous peroxidase activity was removed using $3 \% \quad \mathrm{H}_{2} \mathrm{O}_{2}$ in methanol for $10 \mathrm{~min}$. Sections were transferred to TBS (20 mM Tris pH 7•6, $150 \mathrm{mM} \mathrm{NaCl)}$. The sections were incubated in a humidity chamber for $1 \mathrm{~h}$ in antibody diluted in 1\% BSA in TBS. The primary antibodies are detailed above (see Western blotting section). After incubation the binding sites were labelled with Dako Envision + polymer linked secondary reagent and visualised using Dako DAB + (DakoCytomation, Dako, Campbellfield, Vic, Australia). Nuclei were counterstained with Mayer's haematoxylin and the sections were dehydrated and cover slipped using a resinous mounting agent. Positive controls, which were composite slides with tonsil, breast tumour and ovarian tumour, were included in each run. Negative control slides, where primary antibody was replaced with normal mouse or rabbit IgG serum, were also included.

\section{Statistical analysis}

Statistical analyses were performed using a commercially available statistical software package (Statgraphics Plus version 3.1, Statistical Graphics Corp., Rockville, MD, USA). Student's $t$-test was used to assess statistical significance of the data. Statistical difference was indicated by a $P$ value of $<0 \cdot 05$. Data are expressed as mean \pm s.E.M.

\section{Results}

\section{Analysis of the patient characteristics}

Demographic data of the participants involved in this investigation are summarised in Table 1 . All women in 


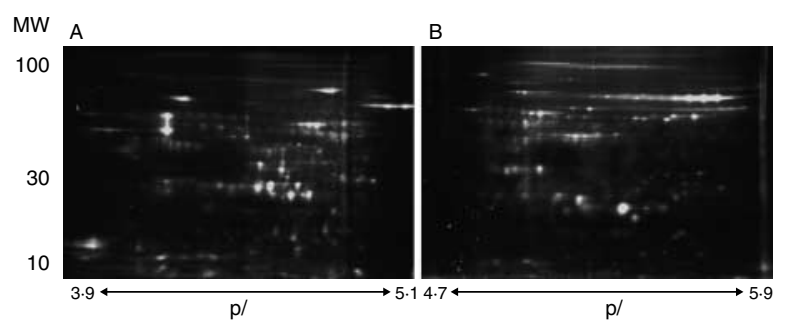

Figure $12 \mathrm{D}$-DIGE analysis of placenta obtained from lean and obese women. (A) $\mathrm{pH}$ 3.9-5.1 and (B) $\mathrm{pH} 4 \cdot 7-5.9$ immobilised $\mathrm{pH}$ gradient strips were used for $\mathrm{p} /$ and $10.5-14 \%$ SDS-PAGE for the second dimension. The $\mathrm{pH}$ values of the IEF system and molecular mass standards (in $\mathrm{kDa}$ ) of the $2 \mathrm{D}$ gels are indicated on the bottom and on the left of the panels respectively.

the lean group had a BMI of $<25 \mathrm{~kg} / \mathrm{m}^{2}$, whereas all women in the obese group had a BMI of $>30 \mathrm{~kg} / \mathrm{m}^{2}$. There were no significant differences in maternal age, fetal birth weight, gravid, parity and gestational age at delivery between the two sample groups.

\section{Identification of differentially expressed proteins using 2D-DIGE}

By using 2D-DIGE, we analysed the placenta proteome from a group of 12 individuals, six lean and six obese. Images for the two $\mathrm{pH}$ ranges are presented in Fig. 1. A total of 38 spots were positively identified; corresponding to 27 distinct proteins. Figure 2 shows the position of these spots in the 2D-DIGE gel. Table 2 displays detailed information about the corresponding proteins identified. This table summarises the protein accession number of identified muscle proteins, Mascot scores, the number of matched peptide sequences, the percentage sequence coverage, molecular mass, $\mathrm{p} I$ value, accession number, average normalised values and fold change of individual proteins affected by obesity.

ANXA5, ATPB, BASP1, FTL, heterogeneous nuclear ribonucleoprotein $\mathrm{C}$ (HNRPC), and VIME were all $\geq 1 \cdot 5$ fold higher in lean patients. On the other hand, A1AT and GRP75 were $\geq 1 \cdot 5$-fold higher in obese patients.

\section{Validation of proteomic results by qRT-PCR and immunoblot analysis}

Western blot and qRT-PCR analyses were used to validate representative findings from the 2D-DIGE analysis. In this study, we used the same six patients whose samples were used in the 2D-DIGE, plus an additional four lean and four obese pregnant women. For normalisation of the data, we used $\beta$-tubulin as the 2D-DIGE showed that this was unchanged between the two sample groups. As shown in Figs 3 and 4, the western blot analysis confirmed the 2D-DIGE data. That is, in obese placenta, the protein expression of cleaved A1AT (Fig. 3A) and GRP75 (Fig. 3B) was significantly higher than lean placenta. On the other hand, lower protein expression of ANXA5 (Fig. 4A), ATPB (Fig. 4B), FTL (Fig. 4C) and VIME (Fig. 4E) was observed in placentas obtained from obese women compared to placentas obtained from lean women. Given that ferritin consists of both a heavy and a light chain, we also chose to analyse FTH. As shown in Fig. 4D, FTH protein expression was also significantly lower in placenta obtained from obese women. For BASP1 and HNRPC, we could not find suitable antibodies, thus qRT-PCR was used to confirm the 2D-DIGE data. As shown in Fig. 5, BASP1 mRNA expression was significantly lower in placentas obtained from obese women. Although the gene expression of $H N R P C$ was lower in obese placentas, this just failed to reach significance $(P=0 \cdot 07)$.

\section{Localisation of A1AT, FTL and FTH in human placenta}

Immunohistochemistry was used to determine the cellular localisation of A1AT, FTL, FTH, ANXA5, ATPB, GRP75 and VIME in human placenta. Placenta exhibited extensive cytoplasmic A1AT staining, which was mainly localised to the syncytiotrophoblast layer and endothelial cells (Fig. 6A). Some A1AT staining was also observed within the villous stoma. FTL (Fig. 6B) and FTH (Fig. 6C) staining was predominantly found

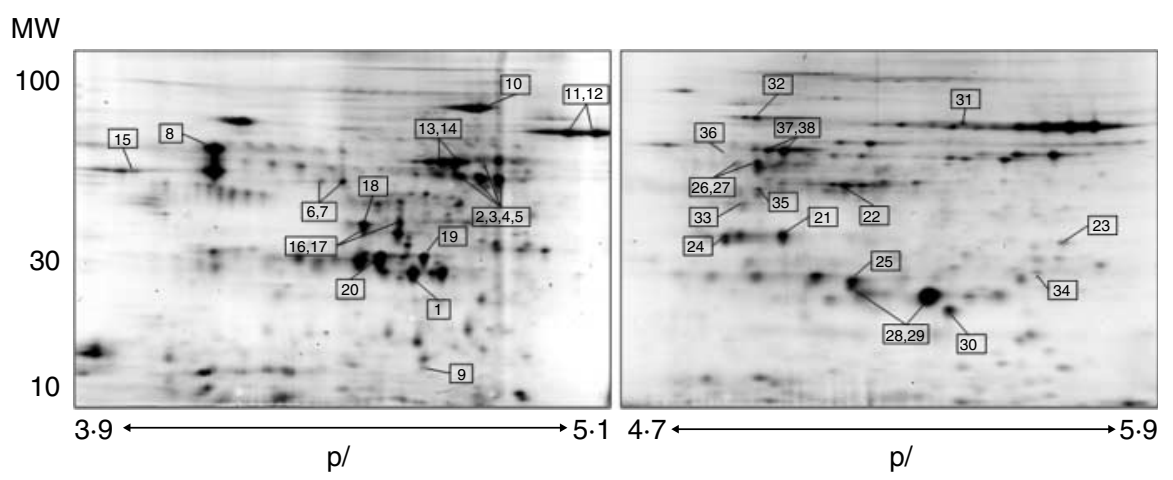

Figure 2 Numbered spots indicate proteins identified by MALDI-TOF MS. See Table 2 for a detailed listing of all proteins identified. 
Table 2 Human placental proteins identified by 2D-DIGE and by MALDI-TOF MS

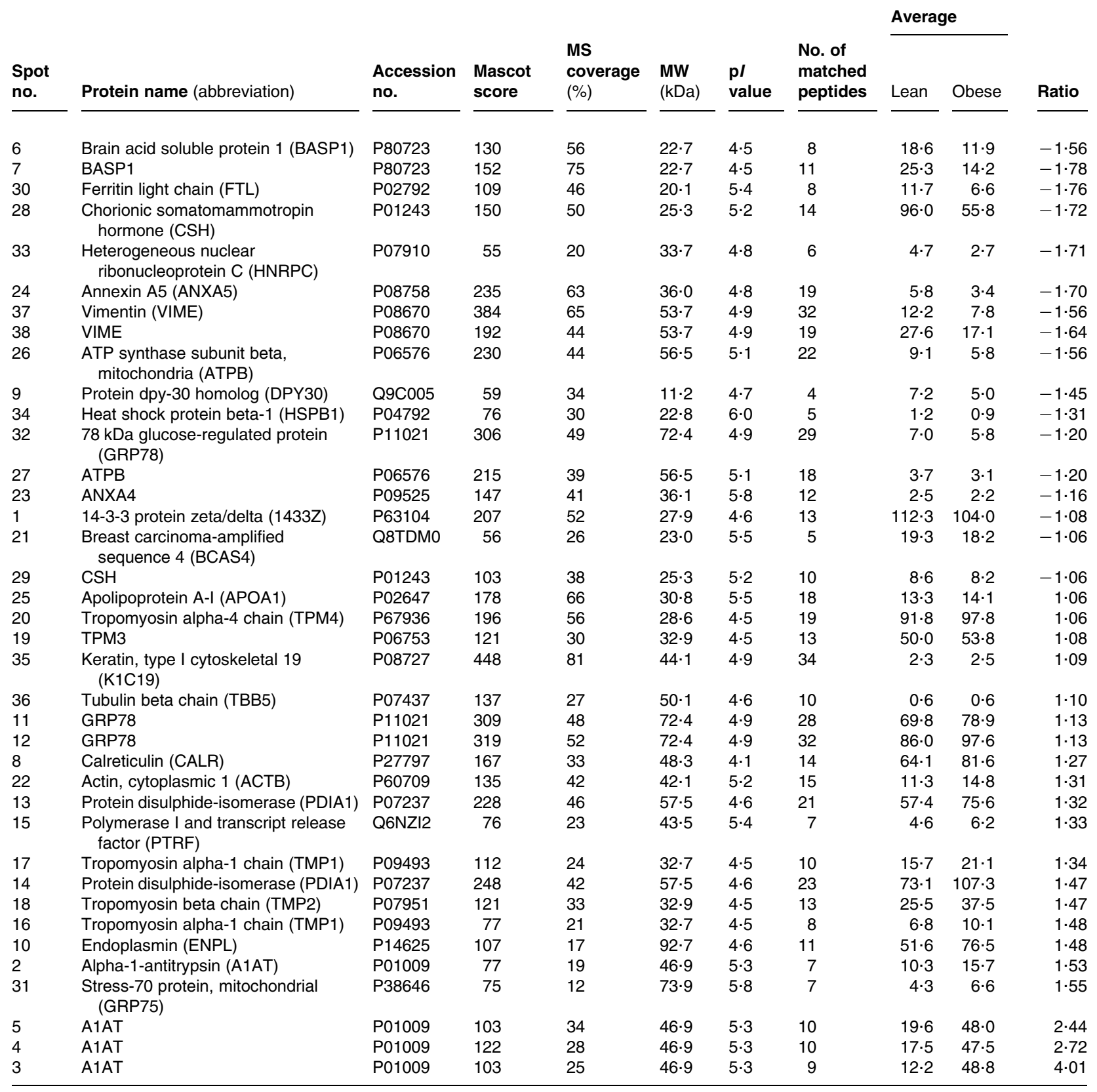

within the villous stroma, although some staining was also observed in the endothelial cells and the syncytiotrophoblasts. For ANXA5 (Fig. 6D) and ATP5B (Fig. 6E), staining was observed in the syncytiotrophoblast layer. GRP75 was localised to the syncytiotrophoblast layer and the endothelial cells (Fig. 6F), and VIME expression was restricted to the villous stroma of the placenta (Fig. 6G). No staining was present in the negative controls (Fig. 6H).

\section{Discussion}

In this study, we have used 2D-DIGE to determine the effect of pre-existing maternal obesity on the protein profile of human placenta. Using MALDI-TOF MS, we were able to successfully identify 40 protein spots, which corresponded to 29 distinct proteins. Maternal obesity was associated with an up-regulation of three proteins; A1AT, serum albumin (ALBU) and GRP75. On the 
A
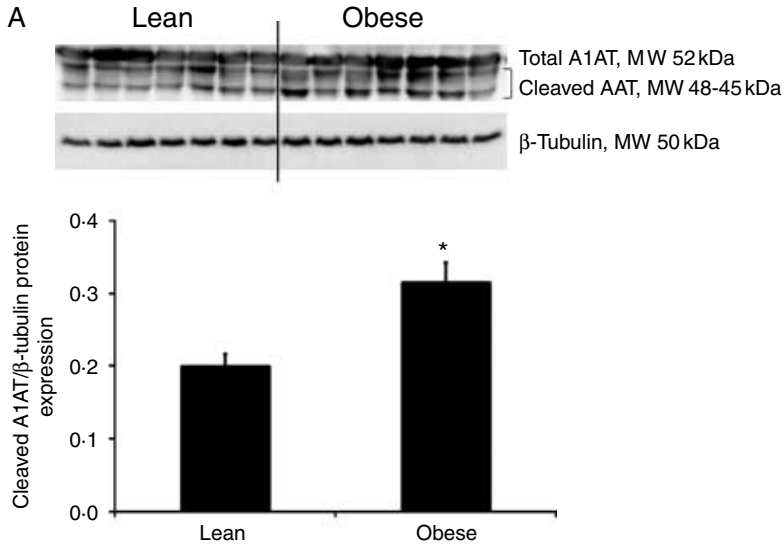

B
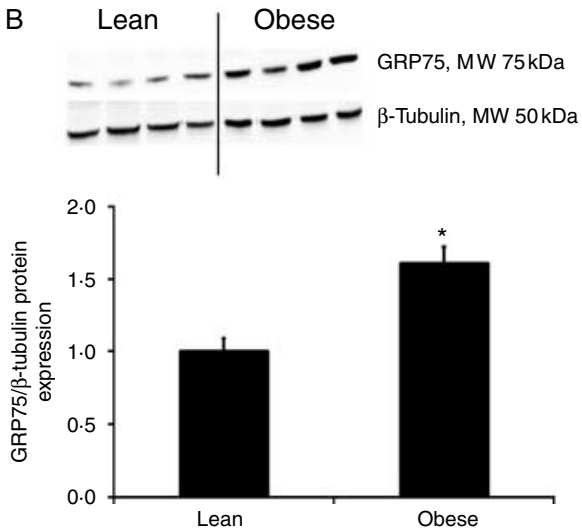

Figure 3 Maternal obesity up-regulates (A) A1AT and (B) GRP75 protein expression in human placenta. Data represent the mean \pm S.E.M. ( $n=10$ per group). ${ }^{\star} P<0.05$ vs lean placenta. A western blot images is shown demonstrating the data for eight patients (four lean and four obese).

other hand, a total of six proteins were found to be down-regulated in the obese placenta. These were ANXA5, ATPB, BASP1, FTL, HNRPC and VIME. Western blot analysis and qRT-PCR analyses of proteins confirmed the 2D-DIGE data. Immunohistochemistry was also used to determine the localisation of protein in human placenta. The roles of these proteins in the regulation of placental function, and how they may influence fetus, are discussed below.

\section{Inflammation}

Exposure of the fetus to an intrauterine inflammatory environment may have short and long-term consequences, including developmental programming of obesity (Taylor \& Poston 2007). In this study, we found evidence of increased inflammation in the placenta. This is consistent with previous studies demonstrating increased accumulation of a heterogeneous macrophage population and pro-inflammatory mediators in obese placentas (Challier et al. 2008).
A1AT is a $52 \mathrm{kDa}$ protease inhibitor belonging to the serpin superfamily (Gettins 2002). It protects tissues from enzymes of inflammatory cells, especially neutrophil elastase, and as such its circulating levels rise upon acute inflammation. However, inactivation of A1AT is associated with cleavage of A1AT $(\sim 4000 \mathrm{kDa}$ lower). In this study, 2D-DIGE revealed a significant increase in cleaved A1AT in obese placenta, which was confirmed by western blotting. In previous studies, term placental syncytiotrophoblast and Hofbauer cells were positively stained for A1AT (Castellucci et al. 1994). Similarly, in this study, A1AT was localised to the syncytiotrophoblasts and the endothelial cells. Pro-inflammatory cytokines $\mathrm{TNF} \alpha$ and interleukin 6 induce A1AT in human amnion (Izumi-Yoneda et al. 2009) and A1AT enhances the magnitude of LPS-induced specific cytokine/chemokine production (Subramaniyam et al. 2010) via the transcription factors NF-KB and AP-1 (Dichtl et al. 2000), which may play an important role in amplification of acute-phase inflammatory reactions. ANXA5 has anti-inflammatory, anti-thrombotic and anti-apoptotic properties (Leon et al. 2006, Ewing et al. 2011). It has previously been detected on trophoblasts in the placenta (Shu et al. 2000) and lower ANXA5 expression has been observed in placentas from pregnancies complicated with preeclampsia (Shu et al. 2000) and fetal growth restriction (Sifakis et al. 2010). Collectively, increased cleaved A1AT and lower ANXA5 expression in obese placentas is suggestive of increased inflammation in the placenta.

\section{Oxidative stress}

Oxidative stress disturbs placental function leading to perpetrations in fetal growth and development (Lappas et al. 2011). Animal models have been very useful to demonstrate that increases in reactive oxygen species (ROS), together with increases in reactive nitrogen species, are clearly related to the induction of malformations in the fetus (Lappas et al. 2011). In this study, we found increased expression of proteins that involved in the generation of ROS as well as increased expression of proteins with antioxidant properties.

Ferritin consists of both a light and a heavy chain (FTL and FTH respectively), which share about $50 \%$ sequence homology (Theil 1987). In this study, 2D-DIGE revealed a decrease in FTL expression in obese placenta, which was confirmed by immunoblotting. In addition, western blotting also revealed a significant decrease in FTH protein expression. The main function of ferritin is to keep iron in a soluble and non-toxic form and to transport it to areas where it is required (MacKenzie et al. 2008). Free iron, via the Fenton reaction, is involved in the formation of the highly damaging ROS hydroxyl radical $(\mathrm{OH} \cdot ;$ Bacic et al. 2008). FTL and FTH were mainly found in the villous 


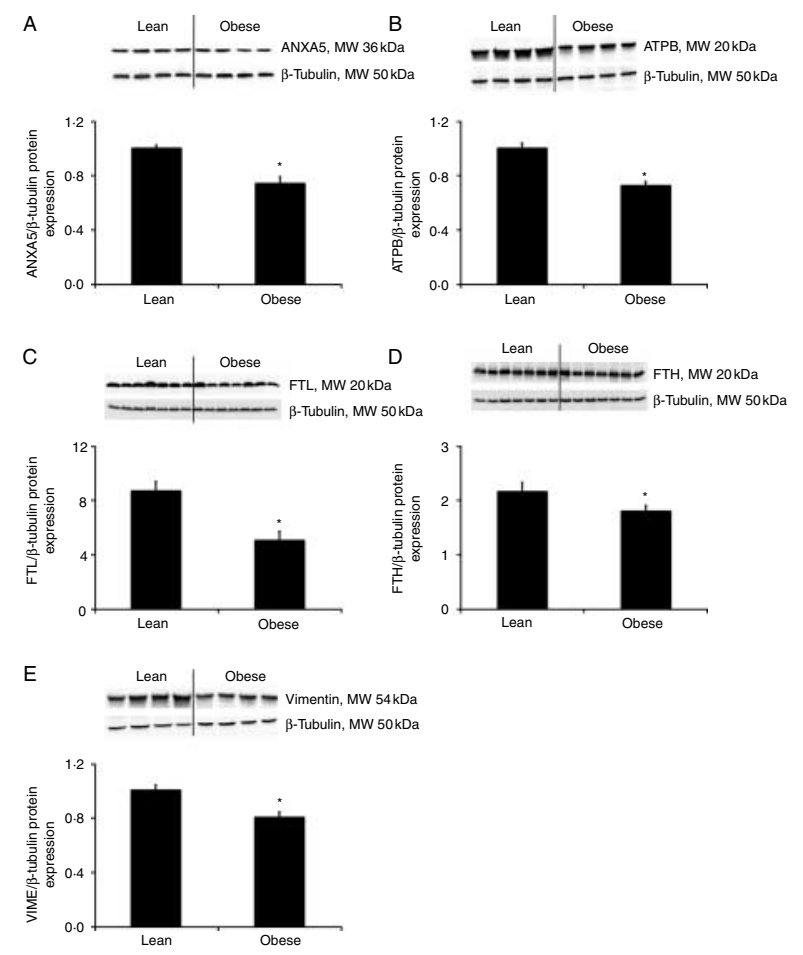

Figure 4 Maternal obesity down-regulates (A) ANXA5, (B) ATPB, (C) FTL, (D) FTH and (E) VIME protein expression in human placenta. Data represent the mean \pm S.E.M. ( $n=10$ per group). ${ }^{\star} P<0.05$ vs lean placenta. A western blot images is shown demonstrating the data for eight patients (four lean and four obese) or 14 patients (seven lean and seven obese).

stroma of the placenta suggesting an important role in the storage of iron in this tissue. The under-expression of ferritin in the placenta may increase free iron leading to increased oxidative stress. In support, studies have shown that there is increased oxidative stress in placentas obtained from obese women (Jarvie et al. 2010). Decreased ferritin expression in the placenta may also affect the rates of iron uptake from the maternal circulation and transfer to the fetal circulation. In support, recent studies have reported evidence of impaired iron status in newborns of women who were obese (Roy et al. 2009). Similarly, iron deficiency has also been reported in infants born to iron-sufficient diabetic mothers (Siddappa et al. 2004). Of clinical importance, iron deficiency in infancy is associated with impaired brain development (Lozoff et al. 1991, Siddappa et al. 2004).

ATP synthase is the universal enzyme that synthesises ATP from ADP and phosphate using the energy stored in a transmembrane ion gradient, with the mitochondrial oxidative phosphorylation machinery playing a crucial role in energy production, generation of ROS and apoptosis. Reduced content and functional capacity of mitochondria are involved in a wide range of human pathologies, including obesity and diabetes (Hojlund et al. 2003, Ritov et al. 2005). The decrease in ATPB expression in obese placentas may lead to mitochondrial dysfunction, leading to an accumulation of lipid metabolites (Vankoningsloo et al. 2006, Mailloux et al. 2007). An accumulation of lipid metabolites could, in turn, partially explain the insulin signalling defects reported in placentas from obese pregnant women (Colomiere et al. 2009). Of note, ATPB is also lower in syncytiotrophoblasts of pre-eclamptic placentas (Hache et al. 2011).

Heat shock proteins act as chaperones, thus having pivotal roles in the cellular stress responses (Prohaszka \& Fust 2004). Of note, GRP75 protein, which is primarily localised to the mitochondria, is triggered by oxidative injury (Wadhwa et al. 2002). Increased GRP75 in obese placentas may be part of a stress-adaptive response that may be critical for the protection against oxidative damage, such as that which may be induced by low FTL and FTH or ATPB observed in this study.

\section{Proliferation and differentiation}

Changes in placental structure and thus function may adversely affect fetal development. We are not aware of any detailed studies that have examined the effect of maternal obesity on placental structure. However, in this study, we found decreased expression of proteins involved in cell integrity and structure.

BASP1 and VIME are proteins implicated in the maintenance of the cell integrity and the stabilisation of the cytoskeletal interactions (Goldman et al. 1996, Korshunova et al. 2008); as such, they play roles in adhesion, migration, survival and cell signalling. HNRPC is a nuclear pre-mRNA binding protein that has also been implicated in cell proliferation (Kim et al. 2003, Schepens et al. 2007) and DPY30 is a protein involved in differentiation (Jiang et al. 2011). All these

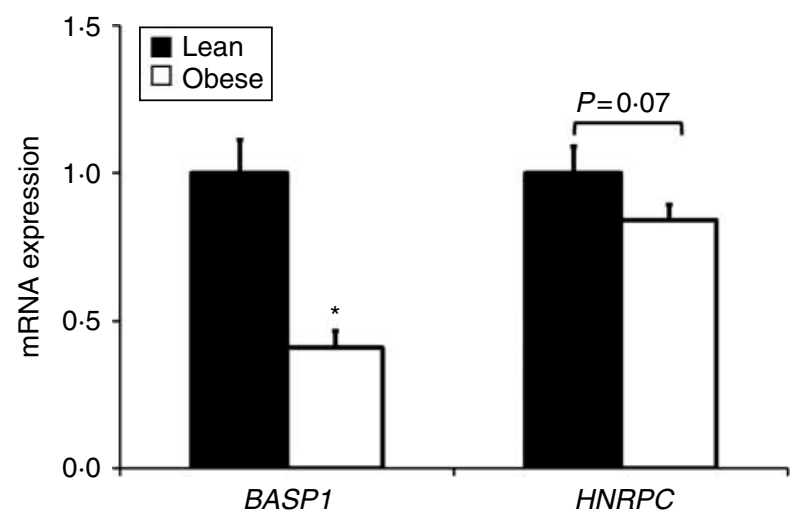

Figure 5 Maternal obesity down-regulates BASP1 and HNRPC mRNA expression in human placenta. Data represent the mean \pm S.E.M. ( $n=10$ per group). ${ }^{*} P<0.05$ vs lean placenta. 

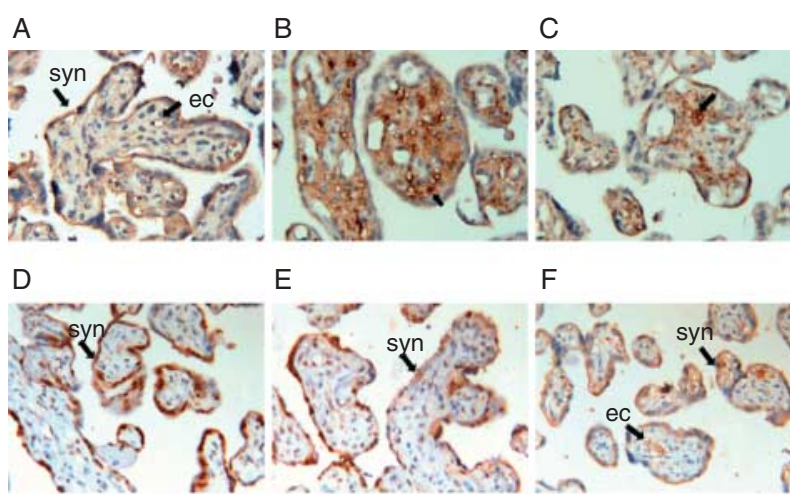

G

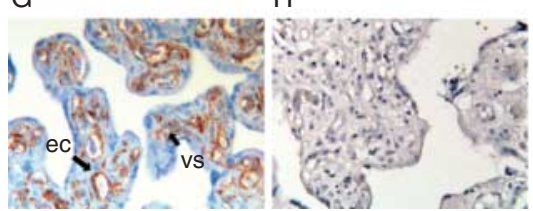

Figure 6 Immunohistochemical localisation of protein in human placenta. (A) A1AT staining was mainly contained in syncytiotrophoblasts (sy) and endothelial cells (ec). Some A1AT staining was also detected in the villous stoma (vs). (B) FTL and (C) FTH were detected mainly in the villous stroma (vs), with some staining detected in the endothelial cells (ec). No FTL staining was detected in the syncytiotrophoblasts (sy). (D) ANXA5 and (E) ATP5B staining was observed in the syncytiotrophoblast layer. (F) GRP75 was localised to the syncytiotrophoblast layer and the endothelial cells. (G) VIME expression was restricted to the villous stroma. $(H)$ No specific staining is seen in the negative control for placenta. Magnification 250X.

proteins were down-regulated in the obese placenta, which is in keeping with recent studies suggesting that placental proliferation may be reduced in relation to increasing maternal early pregnancy BMI (Higgins et al. 2010).

\section{Study limitations}

There are a few limitations to this study. The initial 2D-DIGE data was not stratified according to gender, although equal numbers of males and females were included. However, when the western blotting data was stratified according to gender, there was no difference in expression between males and females (data not shown).

\section{Concluding comments}

In this study, we provide evidence demonstrating that maternal obesity at conception affects the protein profile of human placenta, which may have implications for fetal growth and development. Indeed, obesity reduces oxygen supply to unborn baby (El Baky et al. 2010) and neural tube defects and other developmental anomalies are more common in infants born to obese women (Stothard et al. 2009). Further to this, infants born to obese mothers have increased risks of developing the metabolic syndrome later in life (Boney et al. 2005, Taylor \& Poston 2007). By further understanding the role of maternal diet and body composition on placental function, we may be able to prevent the intergeneration transmission of disease.

\section{Declaration of interest}

The authors declare that there is no conflict of interest that could be perceived as prejudicing the impartiality of the research reported.

\section{Funding}

Dr M L was a recipient of a National Health and Medical Research Council (NHMRC) RD Wright Fellowship (grant number 454777). The work described in this manuscript was funded, in part, by a project grant from NHMRC (grant number 454310). Funding for the ChemiDoc system, xMark Microplate Absorbance Spectrophotometer and Leica Qwin Image Analysis System was provided by the Medical Research Foundation for Women and Babies. Proteomic data analysis described in this work was supported by the use of the Australian Proteomics Computational Facility funded by the Australian NHMRC (grant number 381413).

\section{Author contribution statement}

M L conceived the idea, designed the study, analysed the data and wrote the manuscript. K O, G B, M J B and C R performed the 2D-DIGE experiments. G E R reviewed the manuscript. M P assisted in patient analysis.

\section{Acknowledgements}

The authors gratefully acknowledge the assistance of the Clinical Research Midwives Gabrielle Fleming, Astrid Tiefholz, Lyndall Paolucci, Debra Jinks and Asha Ferguson; and the Obstetrics and Midwifery staff of the Mercy Hospital for Women for their co-operation.

\section{References}

Bacic G, Spasojevic I, Secerov B \& Mojovic M 2008 Spin-trapping of oxygen free radicals in chemical and biological systems: new traps, radicals and possibilities. Spectrochimica Acta. Part A, Molecular and Biomolecular Spectroscopy 69 1354-1366. (doi:10.1016/j.saa.2007. 09.047)

Bhattacharya S, Campbell DM \& Liston WA 2007 Effect of body mass index on pregnancy outcomes in nulliparous women delivering singleton babies. BMC Public Health 7 168. (doi:10.1186/1471-24587-168)

Boney CM, Verma A, Tucker R \& Vohr BR 2005 Metabolic syndrome in childhood: association with birth weight, maternal obesity, and gestational diabetes mellitus. Pediatrics 115 e290-e296. (doi:10.1542/peds.2004-1808)

Castellucci M, Theelen T, Pompili E, Fumagalli L, De Renzis G \& Muhlhauser J 1994 Immunohistochemical localization of serineprotease inhibitors in the human placenta. Cell Tissue Research 278 283-289. (doi:10.1007/BF00414172) 
Challier JC, Basu S, Bintein T, Minium J, Hotmire K, Catalano PM \& Hauguel-de Mouzon S 2008 Obesity in pregnancy stimulates macrophage accumulation and inflammation in the placenta. Placenta 29 274-281. (doi:10.1016/j.placenta.2007.12.010)

Chu SY, Bachman DJ, Callaghan WM, Whitlock EP, Dietz PM, Berg CJ, O'Keeffe-Rosetti M, Bruce FC \& Hornbrook MC 2008 Association between obesity during pregnancy and increased use of health care. New England Journal of Medicine 358 1444-1453. (doi:10.1056/ NEJMoa0706786)

Colagiuri S, Lee CMY, Colagiuri R, Magliano D, Shaw JE, Zimmet PZ \& Caterson ID 2010 The cost of overweight and obesity in Australia. Medical Journal of Australia 192 260-264.

Colomiere M, Permezel M, Riley C, Desoye G \& Lappas M 2009 Defective insulin signaling in placenta from pregnancies complicated by gestational diabetes mellitus. European Journal of Endocrinology 160 567-578. (doi:10.1530/EJE-09-0031)

Dexlin-Mellby L, Sandstrom A, Centlow M, Nygren S, Hansson SR, Borrebaeck CA \& Wingren C 2010 Tissue proteome profiling of preeclamptic placenta using recombinant antibody microarrays. Proteomics. Clinical Applications 4 794-807. (doi:10.1002/prca. 201000001)

Dichtl W, Moraga F, Ares MPS, Crisby M, Nilsson J, Lindgren S \& Janciauskiene S 2000 The carboxyl-terminal fragment of alphalantitrypsin is present in atherosclerotic plaques and regulates inflammatory transcription factors in primary human monocytes. Molecular Cell Biology Research Communications 4 50-61. (doi:10.1006/ mcbr.2000.0256)

Drake AJ \& Reynolds RM 2010 Impact of maternal obesity on offspring obesity and cardiometabolic disease risk. Reproduction 140 387-398. (doi:10.1530/REP-10-0077)

Ehrenberg HM, Mercer BM \& Catalano PM 2004 The influence of obesity and diabetes on the prevalence of macrosomia. American Journal of Obstetrics and Gynecology 191 964-968. (doi:10.1016/j.ajog. 2004.05.052)

El Baky AM, El Shaer TMF, Elwan AE \& Rasmy H 2010 Effect of maternal obesity and passive smoking on neonatal nucleated red blood cells. International Journal of Food Safety, Nutrition and Public Health 3 57-63. (doi:10.1504/IJFSNPH.2010.032035)

Ewing MM, de Vries MR, Nordzell M, Pettersson K, de Boer HC, van Zonneveld AJ, Frostegard J, Jukema JW \& Quax PHA 2011 Annexin A5 therapy attenuates vascular inflammation and remodeling and improves endothelial function in mice. Arteriosclerosis, Thrombosis, and Vascular Biology 31 95-101. (doi:10.1161/ ATVBAHA.110.216747)

Gettins PGW 2002 Serpin structure, mechanism, and function. Chemical Reviews 102 4751-4804. (doi:10.1021/cr010170+)

Goldman RD, Khuon S, Chou YH, Opal P \& Steinert PM 1996 The function of intermediate filaments in cell shape and cytoskeletal integrity. Journal of Cell Biology 134 971-983. (doi:10.1083/jcb.134.4. 971)

Hache S, Takser L, LeBellego F, Weiler H, Leduc L, Forest JC, Giguere Y, Masse A, Barbeau B \& Lafond J 2011 Alteration of calcium homeostasis in primary preeclamptic syncytiotrophoblasts: effect on calcium exchange in placenta. Journal of Cellular and Molecular Medicine 15 654-667. (doi:10.1111/j.1582-4934.2010. 01039.x)

Hass R, Kirchner M, Hollwitz B \& Scharf A 2006 2D-DIGE analysis revealed reduced cytokeratin signaling in placenta with preeclampsia. Signal Transduction 6 190-197. (doi:10.1002/sita. 200500072)

Heslehurst N, Simpson H, Ells LJ, Rankin J, Wilkinson J, Lang R, Brown TJ \& Summerbell CD 2008 The impact of maternal BMI status on pregnancy outcomes with immediate short-term obstetric resource implications: a meta-analysis. Obesity Reviews 9 635-683. (doi:10.1111/j.1467-789X.2008.00511.x)

Heslehurst N, Rankin J, Wilkinson JR \& Summerbell CD 2010 A nationally representative study of maternal obesity in England,
UK: trends in incidence and demographic inequalities in 619323 births, 1989-2007. International Journal of Obesity 34 420-428. (doi:10.1038/ijo.2009.250)

Higgins L, Greenwood SL, Wareing M, Jones RL, Cowley EJ, Sibley CP \& Mills TA 2010 Maternal obesity: does placental cell turnover hold clues to the aetiology of aberrant fetal growth? Reproductive Sciences 17 453. (doi:10.1177/1933719109349780)

Hojlund K, Wrzesinski K, Larsen PM, Fey SJ, Roepstorff P, Handberg A, Dela F, Vinten J, McCormack JG, Reynet C et al. 2003 Proteome analysis reveals phosphorylation of ATP synthase beta-subunit in human skeletal muscle and proteins with potential roles in type 2 diabetes. Journal of Biological Chemistry 278 10436-10442. (doi:10. 1074/jbc.M212881200)

Hull HR, Dinger MK, Knehans AW, Thompson DM \& Fields DA 2008 Impact of maternal body mass index on neonate birthweight and body composition. American Journal of Obstetrics and Gynecology 198 416.e1-6. (doi:10.1016/j.ajog.2007.10.796)

Izumi-Yoneda N, Toda A, Okabe M, Koike C, Takashima S, Yoshida T, Konishi I, Saito S \& Nikaido T 2009 Alpha 1 antitrypsin activity is decreased in human amnion in premature rupture of the fetal membranes. Molecular Human Reproduction 15 49-57. (doi:10.1093/ molehr/gan071)

Jarvie E, Hauguel-de-Mouzon S, Nelson SM, Sattar N, Catalano PM \& Freeman DJ 2010 Lipotoxicity in obese pregnancy and its potential role in adverse pregnancy outcome and obesity in the offspring. Clinical Science 119 123-129. (doi:10.1042/CS20090640)

Jiang H, Shukla A, Wang X-y, Chen W, Bernstein BE \& Roeder RG 2011 Role for Dpy-30 in ES cell-fate specification by regulation of H3K4 methylation within bivalent domains. Cell 144 513-525. (doi:10. 1016/j.cell.2011.01.020)

Kim JH, Paek KY, Choi K, Kim TD, Hahm B, Kim KT \& Jang SK 2003 Heterogeneous nuclear ribonucleoprotein $\mathrm{C}$ modulates translation of c-myc mRNA in a cell cycle phase-dependent manner. Molecular and Cellular Biology 23 708-720. (doi:10.1128/MCB.23.2.708-720. 2003)

Korshunova I, Caroni P, Kolkova K, Berezin V, Bock E \& Walmod PS 2008 Characterization of BASP1-mediated neurite outgrowth. Journal of Neuroscience Research 86 2201-2213. (doi:10.1002/jnr. 21678)

Lappas M, Permezel M \& Rice GE 2003 N-acetyl-cysteine inhibits phospholipid metabolism, proinflammatory cytokine release, protease activity, and nuclear factor-kappaB deoxyribonucleic acidbinding activity in human fetal membranes in vitro. Journal of Clinical Endocrinology and Metabolism 88 1723-1729. (doi:10.1210/jc.2002021677)

Lappas M, Hiden U, Desoye G, Froehlich J, Mouzon SH \& Jawerbaum A 2011 The role of oxidative stress in the pathophysiology of gestational diabetes mellitus. Antioxidants $\mathcal{E}$ Redox Signaling 15 3061-3100. (doi:10.1089/ars.2010.3765)

Leon C, Nandan D, Lopez M, Moeenrezakhanlou A \& Reiner NE 2006 Annexin $\mathrm{V}$ associates with the IFN-gamma receptor and regulates IFN-gamma signaling. Journal of Immunology 176 5934-5942.

Lozoff B, Jimenez E \& Wolf AW 1991 Long-term developmental outcome of infants with iron deficiency. New England Journal of Medicine 325 687-694. (doi:10.1056/NEJM199109053251004)

Ma Y, Zhu MJ, Zhang L, Hein SM, Nathanielsz PW \& Ford SP 2010 Maternal obesity and overnutrition alter fetal growth rate and cotyledonary vascularity and angiogenic factor expression in the ewe. American Journal of Physiology. Regulatory, Integrative and Comparative Physiology 299 R249-R258. (doi:10.1152/ajpregu.00498.2009)

MacKenzie EL, Iwasaki K \& Tsuji Y 2008 Intracellular iron transport and storage: from molecular mechanisms to health implications. Antioxidants E Redox Signaling 10 997-1030. (doi:10.1089/ars.2007. 1893)

Mailloux R, Lemire J \& Appanna V 2007 Aluminum-induced mitochondrial dysfunction leads to lipid accumulation in human hepatocytes: a link to obesity. Cellular Physiology and Biochemistry 20 627-638. (doi:10.1159/000107546) 
McCarthy C, Cotter FE, McElwaine S, Twomey A, Mooney EE, Ryan F \& Vaughan J 2007 Altered gene expression patterns in intrauterine growth restriction: potential role of hypoxia. American Journal of Obstetrics and Gynecology 196 70.e1-70.e6. (doi:10.1016/j.ajog.2006. 08.027)

Prohaszka Z \& Fust G 2004 Immunological aspects of heat-shock proteins-the optimum stress of life. Molecular Immunology 41 29-44. (doi:10.1016/j.molimm.2004.02.001)

Radaelli T, Varastehpour A, Catalano P \& Hauguel-de Mouzon S 2003 Gestational diabetes induces placental genes for chronic stress and inflammatory pathways. Diabetes 52 2951-2958. (doi:10.2337/ diabetes.52.12.2951)

Ritov VB, Menshikova EV, He J, Ferrell RE, Goodpaster BH \& Kelley DE 2005 Deficiency of subsarcolemmal mitochondria in obesity and type 2 diabetes. Diabetes 54 8-14. (doi:10.2337/diabetes. 54.1.8)

Roy SC, Fischer BA, Sridhar V, Blohowiak SE, Coe CL \& Kling PJ 2009 Maternal obesity at delivery: a risk factor for newborn iron deficiency. Pediatric Research 6657.

Schepens B, Tinton SA, Bruynooghe Y, Parthoens E, Haegman M, Beyaert R \& Cornelis S 2007 A role for hnRNP C1/C2 and Unr in internal initiation of translation during mitosis. EMBO Journal $\mathbf{2 6}$ 158-169. (doi:10.1038/sj.emboj.7601468)

Sebire NJ, Jolly M, Harris JP, Wadsworth J, Joffe M, Beard RW, Regan L \& Robinson S 2001 Maternal obesity and pregnancy outcome: a study of 287,213 pregnancies in London. International Journal of Obesity and Related Metabolic Disorders 25 1175-1182. (doi:10.1038/sj. ijo.0801670)

Shu F, Sugimura M, Kanayama N, Kobayashi H, Kobayashi T \& Terao T 2000 Immunohistochemical study of annexin V expression in placentae of preeclampsia. Gynecologic and Obstetric Investigation 49 17-23. (doi:10.1159/000010206)

Siddappa AM, Georgieff MK, Wewerka S, Worwa C, Nelson CA \& Deregnier RA 2004 Iron deficiency alters auditory recognition memory in newborn infants of diabetic mothers. Pediatric Research 55 1034-1041. (doi:10.1203/01.pdr.0000127021.38207.62)

Sifakis S, Soufla G, Koukoura O, Soulitzis N, Koutroulakis D, Maiz N, Konstantinidou A, Melissari E \& Spandidos DA 2010 Decreased annexin A5 mRNA placental expression in pregnancies complicated by fetal growth restriction. Thrombosis Research 125 326-331. (doi:10.1016/j.thromres.2009.11.033)

Stothard KJ, Tennant PW, Bell R \& Rankin J 2009 Maternal overweight and obesity and the risk of congenital anomalies: a systematic review and meta-analysis. Journal of the American Medical Association 301 636-650. (doi:10.1001/jama.2009.113)
Struwe E, Berzl G, Schild R, Blessing H, Drexel L, Hauck B, Tzschoppe A, Weidinger M, Sachs M, Scheler C et al. 2010 Microarray analysis of placental tissue in intrauterine growth restriction. Clinical Endocrinology 72 241-247. (doi:10.1111/j.13652265.2009.03659.x)

Subramaniyam D, Steele C, Kohnlein T, Welte T, Grip O, Matalon S \& Janciauskiene S 2010 Effects of alpha 1-antitrypsin on endotoxininduced lung inflammation in vivo. Inflammation Research $\mathbf{5 9}$ 571-578. (doi:10.1007/s00011-010-0164-x)

Surkan PJ, Hsieh CC, Johansson AL, Dickman PW \& Cnattingius S 2004 Reasons for increasing trends in large for gestational age births. Obstetrics and Gynecology 104 720-726. (doi:10.1097/01.AOG. 0000141442.59573.cd)

Taylor PD \& Poston L 2007 Developmental programming of obesity in mammals. Experimental Physiology 92 287-298. (doi:10.1113/ expphysiol.2005.032854)

Theil EC 1987 Ferritin: structure, gene regulation, and cellular function in animals, plants, and microorganisms. Annual Review of Biochemistry 56 289-315. (doi:10.1146/annurev.bi.56.070187. 001445)

Vankoningsloo S, De Pauw A, Houbion A, Tejerina S, Demazy C, de Longueville F, Bertholet V, Renard P, Remacle J, Holvoet P et al. 2006 CREB activation induced by mitochondrial dysfunction triggers triglyceride accumulation in 3T3-L1 preadipocytes. Journal of Cell Science 119 1266-1282. (doi:10.1242/jcs.02848)

Wadhwa R, Taira K \& Kaul SC 2002 An Hsp70 family chaperone, mortalin/mthsp70/PBP74/Grp75: what, when, and where? Cell Stress E Chaperones 7 309-316. (doi:10.1379/1466-1268(2002) $007<0309$ :AHFCMM > 2.0.CO;2)

Zhang H-h, Wang Y-p \& Chen D-b 2011 Analysis of nitroso-proteomes in normotensive and severe preeclamptic human placentas. Biology of Reproduction 84 966-975. (doi:10.1095/biolreprod.110. 090688)

Zhao YH, Wang DP, Zhang LL, Zhang F, Wang DM \& Zhang WY 2011 Genomic expression profiles of blood and placenta reveal significant immune-related pathways and categories in Chinese women with gestational diabetes mellitus. Diabetic Medicine $\mathbf{2 8}$ 237-246. (doi:10.1111/j.1464-5491.2010.03140.x)

Received in final form 29 January 2012

Accepted 1 February 2012

Made available online as an Accepted Preprint 1 February 2012 